\title{
Clinical and Echocardiographic Correlates of Mortality in Medically Treated Patients With Severe Isolated Aortic Stenosis and Normal Left Ventricular Ejection Fraction
}

\author{
Eddy Barasch, MD; Florentina Petillo, BSc; Simcha Pollack, PhD; \\ Peter D-Y. Rhee, MD; Wendy Stovold; Nathaniel Reichek, MD
}

Background: Many symptomatic patients with severe aortic stenosis (AS) and preserved left ventricular ejection fraction (LVEF) are denied surgery and have a grim prognosis with medical management.

\begin{abstract}
Methods and Results: Between 2003 and 2012, among 550 patients with severe isolated AS and preserved LVEF on transthoracic echocardiography, 241 did not undergo aortic valve replacement (mean age, $83.2 \pm 7.6$ years; $54 \%$ female; aortic valve area index, $0.40 \pm 0.13 \mathrm{~cm}^{2} / \mathrm{m}^{2}$; mean LVEF, $64.8 \pm 7.6 \%$ ) and $67 \%$ presented with cardiac symptoms. At a mean follow-up of $25.5 \pm 25.1$ months, 134 patients (56\%) had died. Survival at 1, 5 and 9.5 years was $71 \%, 28 \%$ at $12 \%$, respectively. Median survival was 36.3 months (95\% confidence interval [Cl]: 27.2-42.4 months). In unadjusted analyses, age, heart failure, hypertension, renal insufficiency, left atrial size, pulmonary artery systolic pressure (PASP), relative wall thickness and LV mass/LV end diastolic volume ratio were associated with mortality. On multivariate analysis adjusted for all significant univariate predictors, age $\geq 78$ years, history of hypertension, left atrial diameter $\geq 40 \mathrm{~mm}$ and PASP $\geq 42 \mathrm{mmHg}$ gave a joint area under the curve of 0.80 ( $95 \% \mathrm{Cl}: 0.73-0.86$ ) for mortality.
\end{abstract}

Conclusions: In medically treated patients with severe isolated AS and preserved LVEF, older age, history of hypertension, and echo-Doppler variables reflecting LV diastolic dysfunction are independent predictors of death. (Circ J 2014; 78: 232-239)

Key Words: Aortic stenosis; Echocardiography; Prognosis

$\mathbf{T}$ he prevalence of aortic valve (AV) structural changes and calcification increases with age such that approximately $30 \%$ of individuals over the age of 65 years have AV sclerosis while $4 \%$ have overt aortic stenosis (AS). ${ }^{1}$ In apparently healthy subjects $75-86$ years old, the prevalence of moderate to severe AS increases from $2.5 \%$ at $75-76$ years to $8.1 \%$ at $85-86$ years. ${ }^{2}$ The natural history of AS is well established: after the onset of angina pectoris, syncope or heart failure, annual mortality approaches $25 \%$ with an average survival of 2-3 years. ${ }^{3}$ Because there is no effective medical therapy, AV replacement (AVR), whether performed by surgical or percutaneous approach, represents the only definitive therapy.

Among patients who otherwise meet criteria for AVR, surgery is not performed in between $33 \%$ and $61 \% .{ }^{4,5}$ Because the mortality of these patients is approximately twice that of similar patients undergoing AVR, ${ }^{6}$ and the main reasons for surgi- cal ineligibility are comorbidities that significantly increase operative risk, ${ }^{7}$ refining risk stratification of these patients is important. Objective reassessment of such patients may indicate appropriateness of surgery in up to one-quarter of them, ${ }^{8}$ while transcatheter aortic valve implantation (TAVI) has become increasingly available as a potential alternative to surgery. ${ }^{9}$

A number of recent studies have described clinical and echocardiographic predictors of death and major cardiac adverse events in patients with severe AS but most have examined the post-surgical ${ }^{10}$ or post-TAVI outcome. ${ }^{11}$ Prior studies have enrolled patients with severe AS regardless of left ventricular ejection fraction (LVEF). ${ }^{12,13}$ In several, LVEF was strongly associated with outcome in both unoperated and operated patients with AS. $4,5,14$

We sought to identify echocardiographic, clinical and laboratory variables associated with all-cause mortality in medically treated patients with severe isolated AS and normal LVEF.

Received July 4, 2013; revised manuscript received August 9, 2013; accepted September 10, 2013; released online October 30, 2013 Time for primary review: 21 days

St. Francis Hospital, Heart Center/State University of New York at Stony Brook, Department of Research and Education, Roslyn, NY, USA

Mailing address: Eddy Barasch, MD, St. Francis Hospital/SUNY at Stony Brook, Department of Research, 100 Port Washington Blvd, Roslyn, NY 11576, USA. E-mail: eddy.barasch@chsli.org

ISSN-1346-9843 doi:10.1253/circj.CJ-13-0821

All rights are reserved to the Japanese Circulation Society. For permissions, please e-mail: cj@j-circ.or.jp 


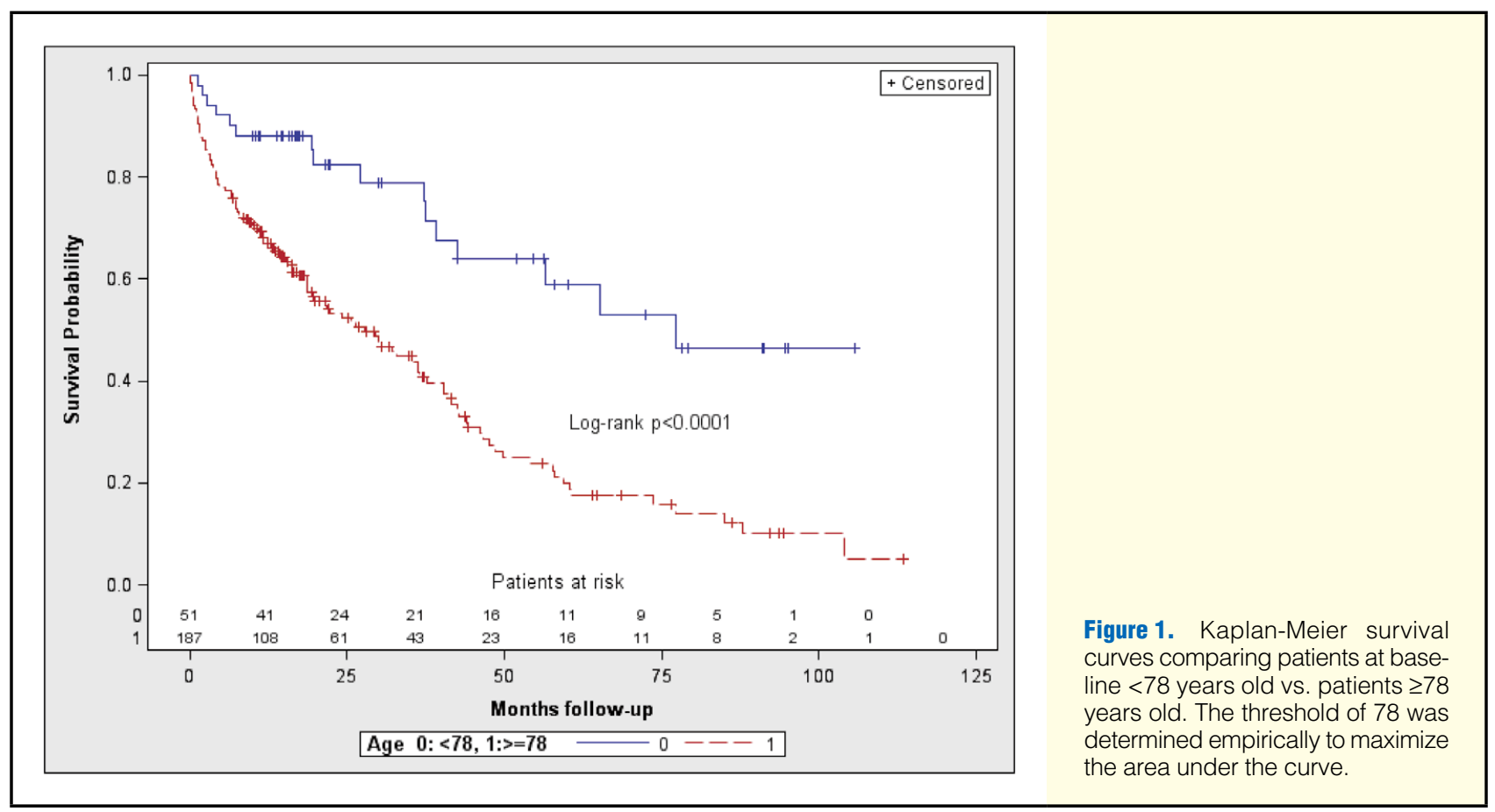

We hypothesized that, given the high prevalence of heart failure in this patient type, variables indicative of impaired LV diastolic function might have prognostic value.

\section{Methods}

\section{Subjects}

Between 2003 and 2012, 3,603 patients had at least 1 transthoracic echocardiogram done for evaluation of AS at St. Francis Hospital-The Heart Center, Roslyn, New York, of whom 550 had severe isolated AS, normal sinus rhythm, and preserved LVEF. Two hundred and forty-one did not undergo AVR and met inclusion criteria: aortic valve area (AVA) $<0.60 \mathrm{~cm}^{2} / \mathrm{m}^{2}$, LVEF $>50 \%$, sinus rhythm, no more than mild mitral or aortic regurgitation and no prosthetic valves.

\section{Echocardiography}

Transthoracic echocardiography was performed using a Phillips 5500, Phillips IE-33 or GE Vivid 7 echocardiograph. LVEF was calculated using the biplane Simpson's rule method and AVA was determined using the continuity equation. Mitral annular calcification was defined as an intense echo-producing structure located at the junction of the atrioventricular groove and posterior mitral leaflet on the parasternal long axis, apical 4-chamber or parasternal short-axis view. ${ }^{15}$ Severity was qualitatively determined in parasternal short axis view at the level of the mitral annulus as: "mild" (focal, limited increased echodensity of the mitral annulus); "moderate" (marked echodensity involving more than one-third but less than one-half of the ring circumference); or "severe" (marked echodensity involving half or more of the circumference of the ring or with intrusion of the calcification into the LV inflow tract). ${ }^{16} \mathrm{LV}$ diastolic function and mitral annular motion were investigated on tissue Doppler imaging using standard methods. E/E' at the septal aspect of the mitral annulus $(\mathrm{E} / \mathrm{E}$ 'septal $) \geq 15$ was taken to indicate elevated LV filling pressure. ${ }^{17}$ Peak pulmonary artery systolic pressure (PASP) was estimated from right ventricular systolic pressure, adding right atrial pressure estimated using images of the inferior vena cava. Doppler variables were reported as an average of 3 cardiac cycles. Cuff blood pressure (BP) was also measured at the time of the study. Echocardiographic data were analyzed off-line on a dedicated reading station (AGFA, HeartLab) by a single research sonographer (F.P.). LV mass was calculated using the American Society of Echocardiography method. ${ }^{18}$ Systemic vascular resistance, systemic arterial compliance, energy loss index and valvulo-arterial impedance were calculated using the described methods. ${ }^{19}$

\section{Clinical Variables}

Hypertension was defined as BP $>140 / 90 \mathrm{mmHg}$ or a history of hypertension and current anti-hypertensive medications. Diabetes mellitus was defined as fasting blood sugar $>126 \mathrm{mg} / \mathrm{dl}$ on 2 occasions or treatment with anti-diabetic agents. Renal insufficiency was defined as serum creatinine $\geq 1.3 \mathrm{mg} / \mathrm{dl}$. Coronary artery disease was defined as a history of angina pectoris, myocardial infarction, a positive stress test, angiographic evidence of coronary artery disease, coronary intervention, or coronary artery bypass surgery. Chronic obstructive lung disease (COPD) was defined as the presence of poorly reversible airflow limitation. To enable assessment of LV diastolic function, only patients with normal sinus rhythm and no more than mild mitral annular calcification were enrolled.

Patients were followed for a mean period of 25.5 \pm 25.1 months (range, 0.07-113.4 months).

Outcome endpoints were all-cause mortality and AVR. Mortality data were extracted from medical records and the Social Security Death Index. The most recent evaluation of patient survival status was performed in June 2012. The study was approved by the Institutional Review Board of St. Francis Hospital.

\section{Statistical Analysis}

Continuous variables were compared between patient subgroups at baseline using independent t-test. Fisher's exact test 


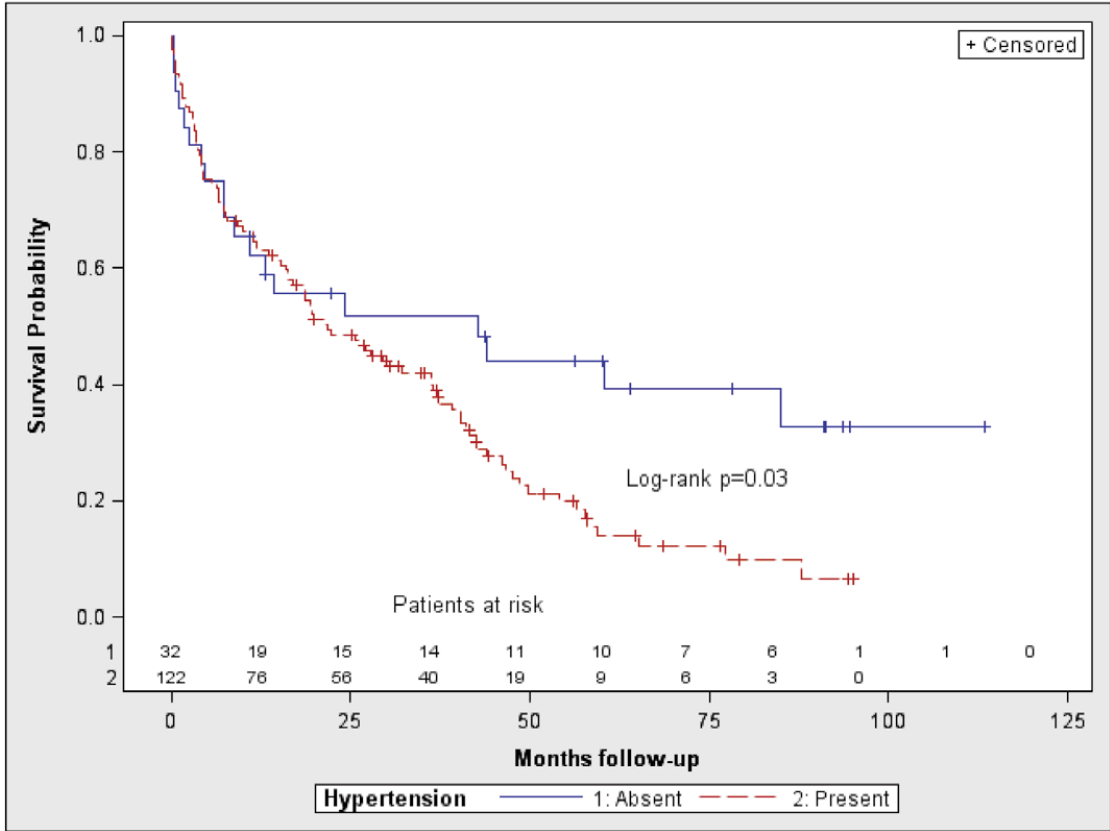

Figure 2. Kaplan-Meier survival curves comparing patients with arterial hypertension at baseline vs. those without it.

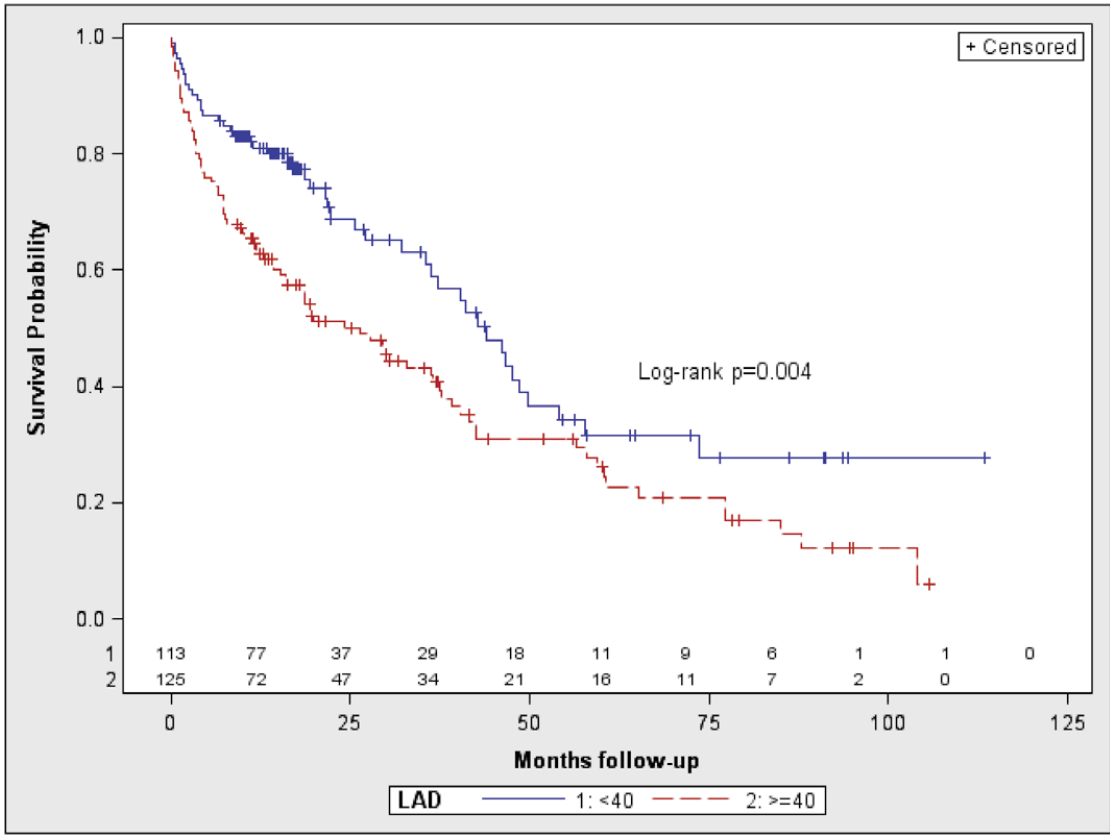

Figure 3. Kaplan-Meier survival curves comparing patients with left atrial antero-posterior diameter (LAD) $<40 \mathrm{~mm}$ vs. patients with $\mathrm{LAD} \geq 40 \mathrm{~mm}$.

or chi-squared test was used for categorical variables. To minimize bias due to missing data, multiple imputation (MI) was used, via SAS Proc MI, to create 20 imputed data sets. ${ }^{20}$ Survival analysis (all-cause mortality, with time measured from the first echocardiogram) was done using a Cox proportional hazards regression model applied to individual variables and a series of multivariate models adjusted for demographic, clinical and significant echo variables. Area under the curve (AUC-time; the 'c' statistic taking into account the time to death) was calculated from the output of the Cox proportional hazards regres- sion as is required for survival analysis in the presence of censoring. The proportional hazards assumption was tested in the final Cox models. The prognostic utility of candidate predictors was determined by the P-value of each continuous variable in a univariate Cox proportional hazards regression model, while AUC-t was measured from the output of the survival model results.

For clinical application of the results in the multivariate models (especially hazard ratios [HR]), each variable was dichotomized to determine optimal thresholds for each predictor, 


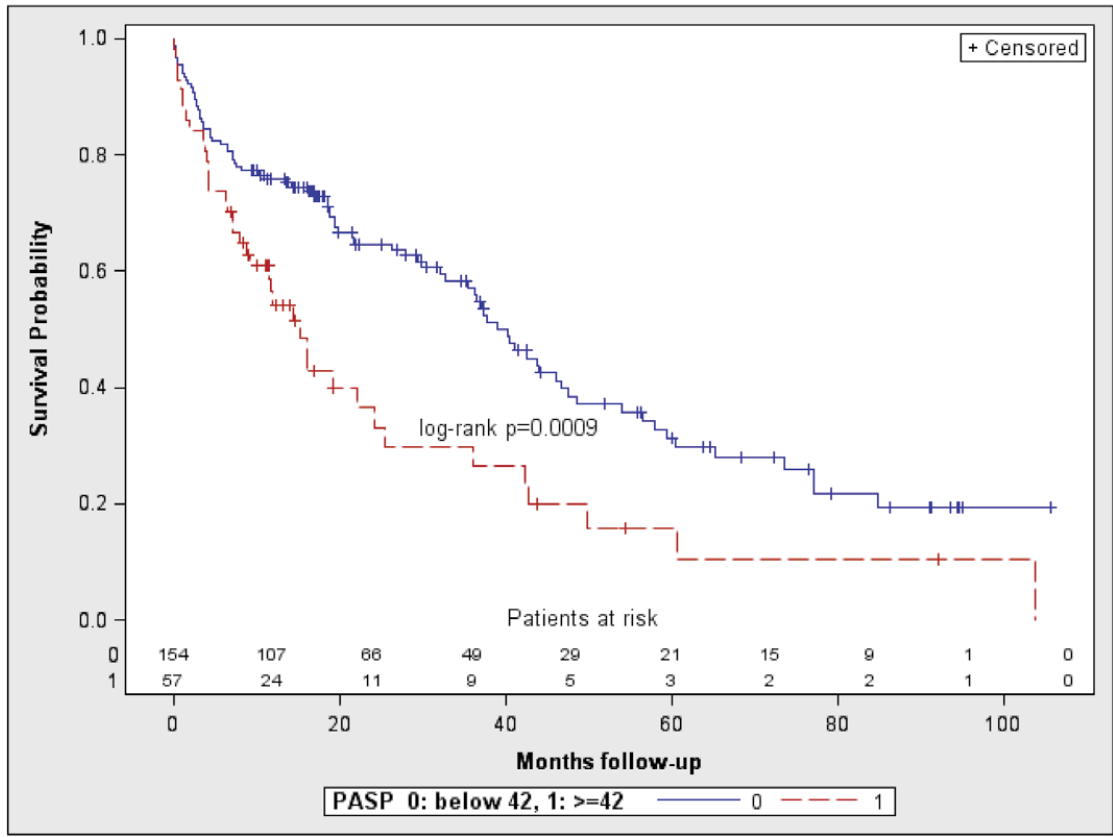

Figure 4. Kaplan-Meier survival curves comparing patients with pulmonary artery systolic pressure (PASP) $<42 \mathrm{mmHg}$ vs. patients with $P A S P \geq 42 \mathrm{mmHg}$.

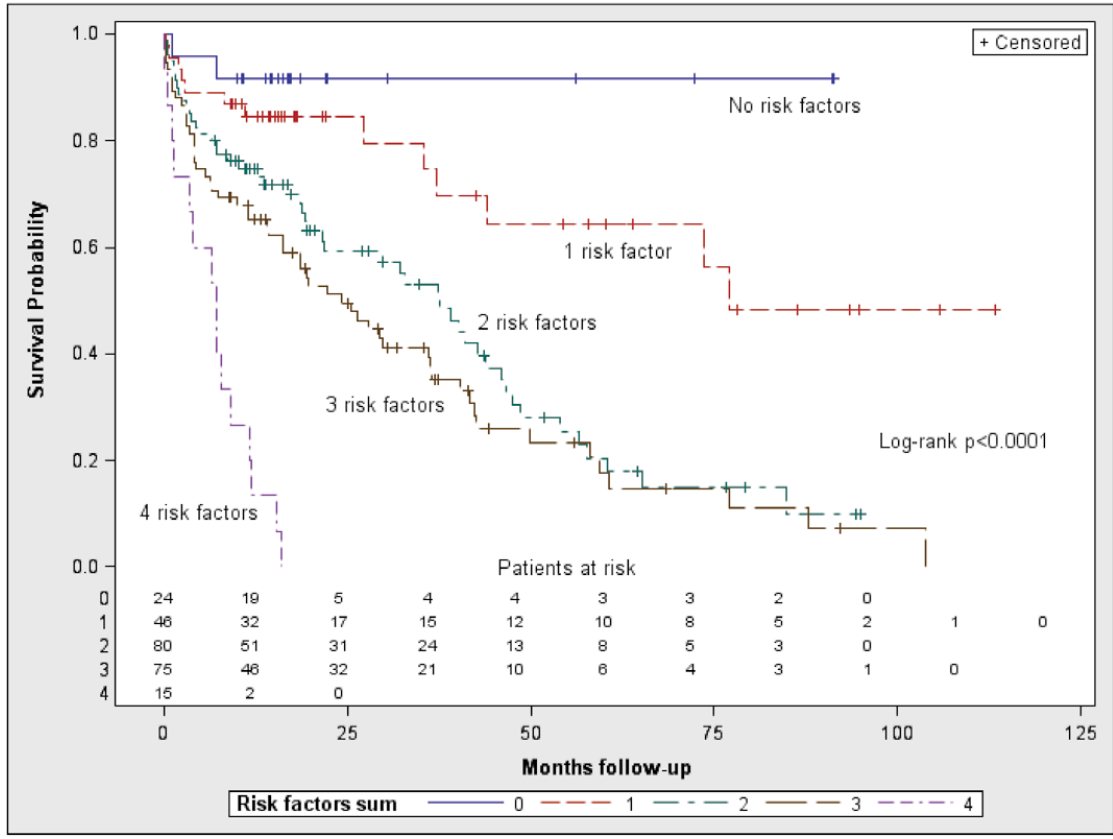

Figure 5. Overall survival as a function of the number of risk factors (ie, age, hypertension, left atrial diameter and pulmonary artery systolic pressure).

and exhaustive testing was done of all possible cut-off points for the set of variables in the model. Thresholds were chosen that maximized the AUC-t and minimized the sum of individual P-values. Selected thresholds were tested in a multivariate model controlling for known clinical predictors of survival (heart failure, hypertension, renal insufficiency, diabetes and hypercholesterolemia), both individually and simultaneously. The variables that remained significant were entered into a multivariate Cox proportional hazards regression model including the clinical and echocardiographic variables associated with time to death. These variables were combined, yielding a parsimonious multivariate model. A measure of risk was developed and tested that was defined as the number of variables exceeding its threshold. $\mathrm{P}<0.05$ was deemed statistically significant. All analyses were conducted using SAS 9.3 (SAS Institute, Cary, NC, USA).

Mean inter-rater reliability as measured by intra-class correlation was 0.90 for 10 echo-Doppler variables remeasured in a set of 25 randomly chosen patients at a 2-week interval. 


\begin{tabular}{|c|c|c|c|c|c|}
\hline \multirow[t]{2}{*}{ Variable } & \multirow{2}{*}{$\begin{array}{l}\text { All patients } \\
\qquad \mathrm{n}=\mathbf{2 4 1}\end{array}$} & \multirow{2}{*}{$\begin{array}{c}\text { Survivors } \\
n=107\end{array}$} & \multirow{2}{*}{$\begin{array}{c}\text { Non-survivors } \\
n=134\end{array}$} & \multicolumn{2}{|c|}{$\begin{array}{l}\text { Cox proportional hazards } \\
\text { survival analysis }\end{array}$} \\
\hline & & & & P-value & HR (95\% Cl) \\
\hline Age (years) & $83.2 \pm 7.6$ & $80.8 \pm 9.3$ & $85.2 \pm 6.4$ & $<0.0001$ & $0.73(0.66-0.79)$ \\
\hline Weight (kg) & $70.8 \pm 19.2$ & $69.7 \pm 17.3$ & $71.7 \pm 20.8$ & 0.98 & $0.50(0.5-0.62)$ \\
\hline Height (cm) & $164.6 \pm 10.7$ & $163.3 \pm 10.2$ & $165.6 \pm 10.9$ & 0.28 & $0.54(0.49-0.62)$ \\
\hline BMI $\left(\mathbf{k g} / \mathrm{m}^{2}\right)$ & $26 \pm 5.8$ & $26 \pm 5.4$ & $26 \pm 6.2$ & 0.57 & $0.53(0.5-0.65)$ \\
\hline $\operatorname{BSA}\left(\mathrm{m}^{2}\right)$ & $1.8 \pm 0.3$ & $1.8 \pm 0.2$ & $1.8 \pm 0.3$ & 0.85 & $0.50(0.5-0.61)$ \\
\hline Heart rate (beats/min) & $71.9 \pm 15$ & $68.9 \pm 14.1$ & $74.3 \pm 15.7$ & 0.005 & $0.60(0.54-0.66)$ \\
\hline SBP (mmHg) & $134 \pm 24.6$ & $135.5 \pm 23$ & $132.5 \pm 26.1$ & 0.07 & $0.60(0.5-0.71)$ \\
\hline $\mathrm{DBP}(\mathrm{mmHg})$ & $64 \pm 14$ & $64.6 \pm 14.2$ & $63.4 \pm 13.8$ & 0.01 & $0.62(0.52-0.72)$ \\
\hline \multicolumn{6}{|l|}{ Dichotomous variables } \\
\hline Male & 46.5 & 43.9 & 48.5 & 0.47 & $0.41(0.38-0.5)$ \\
\hline Smoker & 36.8 & 30.8 & 38.9 & 0.36 & $0.40(0.36-0.48)$ \\
\hline Hypertension & 79.7 & 67.5 & 84.1 & 0.02 & $0.54(0.44-0.68)$ \\
\hline Diabetes & 27 & 17.5 & 30.4 & 0.12 & $0.39(0.34-0.47)$ \\
\hline Angina $^{\dagger}$ & 20.8 & 33.3 & 16.4 & 0.02 & $0.47(0.34-0.62)$ \\
\hline Syncope $^{\dagger}$ & 11.4 & 10.3 & 11.8 & 0.79 & $0.30(0.29-0.4)$ \\
\hline Heart failure $^{\dagger}$ & 55.9 & 35.9 & 62.8 & 0.003 & $0.61(0.49-0.71)$ \\
\hline Renal insufficiency & 39.3 & 20.7 & 44.3 & 0.02 & $0.5(0.41-0.58)$ \\
\hline COPD & 25 & 15 & 85 & $<0.0001$ & $0.43(0.37-0.47)$ \\
\hline CAD & 58.8 & 57.5 & 59.3 & 0.84 & $0.4(0.37-0.5)$ \\
\hline PTCA/stents & 28.3 & 33.3 & 26.5 & 0.42 & $0.41(0.35-0.54)$ \\
\hline CABG & 12.6 & 17.9 & 10.7 & 0.24 & $0.29(0.27-0.31)$ \\
\hline Antiplatelets & 53.5 & 63.6 & 50.5 & 0.18 & $0.42(0.38-0.53)$ \\
\hline$\beta$-blocker & 54.9 & 54.5 & 55 & 0.96 & $0.43(0.37-0.54)$ \\
\hline Calcium channel blockers & 29.6 & 30.3 & 29.4 & 0.92 & $0.37(0.35-0.53)$ \\
\hline Statins & 43.7 & 48.5 & 42.2 & 0.52 & $0.42(0.37-0.53)$ \\
\hline ARB & 14.8 & 18.2 & 13.8 & 0.53 & $0.33(0.3-0.48)$ \\
\hline ACEI & 26.1 & 33.3 & 23.9 & 0.28 & $0.40(0.34-0.56)$ \\
\hline Digoxin & 13.4 & 6.1 & 15.6 & 0.16 & $0.34(0.3-0.39)$ \\
\hline Diuretics & 50 & 39.4 & 53.2 & 0.16 & $0.28(0.25-0.31)$ \\
\hline
\end{tabular}

Data given as mean \pm SD or \%. tOn admission.

ACEI, angiotensin-converting enzyme inhibitors; ARB, angiotensin receptor blockers; BMI, body mass index; BSA, body surface area; $C A B G$, coronary artery bypass grafting; $C A D$, coronary artery disease; $\mathrm{Cl}$, confidence interval; COPD, chronic obstructive pulmonary disease; DBP, diastolic blood pressure; HR, hazard ratio; PTCA, percutaneous transluminal coronary angioplasty; SBP, systolic blood pressure.

\section{Results}

Of the 550 patients who met enrollment criteria, 241 (44\%) did not undergo AVR. Mean age was $83.2 \pm 7.6$ years, $54 \%$ were female, mean AVA index was $0.40 \pm 0.13 \mathrm{~cm}^{2} / \mathrm{m}^{2}$, and mean LVEF was $64.8 \pm 7.6 \%$. A total of 102 patients $(42 \%)$ presented with heart failure symptoms, $45(19 \%)$ with angina or acute myocardial infarction, and $15(6 \%)$ with syncope. Fifty-three patients $(22 \%)$ presented with non-cardiac diagnoses (ie, abdominal pain, orthopedic reasons, acute renal insufficiency, dehydration, weakness, etc.) and the reason for admission could not be determined with certainty in 24 patients (11\%). Fiftyeight patients refused surgery, 71 were denied surgery because of multiple comorbidities, 58 because of extremely advanced age and frailty, 34 due to family refusal and 20 for unknown reasons.

After a mean follow-up of $25.5 \pm 25.1$ months, 134 patients $(56 \%)$ had died. Median survival was 36.3 months (95\% confidence interval [CI]: 27.2-42.4). Kaplan-Meier product-limit survival probability for 1-year survival was $71 \%, 5$-year survival, 28\% and 9.5-year survival, 12\% (Figures 1-5).

Non-survivors were older and had higher prevalence of hypertension, COPD, heart failure, and renal insufficiency than survivors (Table 1). They also had more echocardiographic LV structural and geometric remodeling, more severe LV diastolic dysfunction, higher PASP and a trend toward more severe AS with similar LVEF, vascular load and global afterload as compared to survivors (Table 2).

To exclude COPD as a potential cause of pulmonary hypertension, we compared patients with and without a history of COPD, and no difference in PASP was found between the 2 groups $(\mathrm{P}=0.82)$.

Among LV diastolic function indices, E/E' septal was significantly associated with death. One-year survival for E/E' septal $\leq 15$ $(n=81)$ was $77 \%$ vs. $66 \%$ for $E / E$ ' septal $>15(n=120$; log-rank $\mathrm{P}=0.02$; HR low E/E' septal, 0.62; 95\% CI: 0.40-0.94, $\mathrm{P}=0.0006)$. In highly adjusted models, however, E/E' septal was not an independent correlate of death.

Table 3 lists the adjusted multivariate HR and AUC-t for independent correlates of time to death. Two clinical and 2 echo correlates of all-cause death, age, history of hypertension, left atrial diameter (LAD) and PASP, remained significant after controlling for the other candidate variables. Cut-off points of 78 years for age, history of hypertension, 40-mm 
Table 2. Echocardiographic Variables

\begin{tabular}{|c|c|c|c|c|c|c|}
\hline \multirow[t]{2}{*}{ Variable } & \multirow{2}{*}{$\begin{array}{c}\text { All patients } \\
n=241\end{array}$} & \multirow{2}{*}{$\begin{array}{c}\text { Survivors } \\
\mathrm{n}=107\end{array}$} & \multirow{2}{*}{$\begin{array}{c}\text { Non-Survivors } \\
n=134\end{array}$} & \multirow{2}{*}{$\begin{array}{c}\text { t-test } \\
\text { P-value }\end{array}$} & \multicolumn{2}{|c|}{$\begin{array}{c}\text { Cox proportional hazards } \\
\text { survival analysis }\end{array}$} \\
\hline & & & & & P-value & $\mathrm{HR}(95 \% \mathrm{Cl})$ \\
\hline LVDD (mm) & $40.1 \pm 5.9$ & $39.7 \pm 5.4$ & $40.5 \pm 6.3$ & 0.34 & 0.51 & $0.53(0.5-0.64)$ \\
\hline LVSD (mm) & $26.8 \pm 6.0$ & $26.2 \pm 5.7$ & $27.3 \pm 6.1$ & 0.16 & 0.19 & $0.55(0.5-0.64)$ \\
\hline IVSd (mm) & $15.2 \pm 3$ & $15.2 \pm 3.5$ & $15.2 \pm 2.7$ & 0.99 & 0.07 & $0.57(0.49-0.66)$ \\
\hline PWd (mm) & $12.1 \pm 1.9$ & $11.7 \pm 1.8$ & $12.5 \pm 1.9$ & 0.0005 & 0.0065 & $0.62(0.52-0.7)$ \\
\hline MWT (mm) & $13.7 \pm 2.1$ & $13.4 \pm 2.3$ & $13.9 \pm 2$ & 0.12 & 0.01 & $0.61(0.52-0.69)$ \\
\hline LVMi $\left(g / m^{2}\right)$ & $116.3 \pm 32$ & $112.5 \pm 31.4$ & $119.3 \pm 32.5$ & 0.11 & 0.14 & $0.56(0.5-0.65)$ \\
\hline LVEDVi $\left(\mathrm{ml} / \mathrm{m}^{2}\right)$ & $39.2 \pm 12.4$ & $39.7 \pm 12$ & $38.7 \pm 12.8$ & 0.56 & 0.23 & $0.56(0.5-0.68)$ \\
\hline LVESVi (ml/m²) & $13.8 \pm 5.6$ & $13.8 \pm 5.6$ & $13.7 \pm 5.6$ & 0.92 & 0.95 & $0.50(0.5-0.61)$ \\
\hline SVI (ml/beat) & $35 \pm 9.1$ & $35.3 \pm 8.7$ & $34.8 \pm 9.5$ & 0.73 & 0.19 & $0.56(0.51-0.65)$ \\
\hline LVEF (\%) & $64.8 \pm 7.6$ & $65.3 \pm 7.4$ & $64.5 \pm 7.8$ & 0.41 & 0.16 & $0.57(0.5-0.66)$ \\
\hline Relative wall thickness & $0.62 \pm 0.14$ & $0.60 \pm 0.12$ & $0.64 \pm 0.15$ & 0.03 & 0.004 & $0.62(0.52-0.68)$ \\
\hline LVMi/LVEDVi & $3.2 \pm 1.2$ & $3 \pm 1.1$ & $3.3 \pm 1.3$ & 0.05 & 0.004 & $0.61(0.54-0.66)$ \\
\hline LAD (mm) & $40.8 \pm 7$ & $38.1 \pm 6.3$ & $43.1 \pm 7.5$ & $<0.0001$ & 0.0004 & $0.64(0.56-0.71)$ \\
\hline LASA $\left(\mathrm{cm}^{2}\right)$ & $22.9 \pm 5.5$ & $21.3 \pm 4.8$ & $24.1 \pm 6.1$ & $<0.0001$ & 0.004 & $0.60(0.54-0.7)$ \\
\hline LAVI $\left(\mathrm{ml} / \mathrm{m}^{2}\right)$ & $46.7 \pm 15.7$ & $42.2 \pm 12.8$ & $50.1 \pm 18$ & 0.0005 & 0.002 & $0.64(0.56-0.72)$ \\
\hline $\mathrm{E}(\mathrm{cm} / \mathrm{s})$ & $91.2 \pm 28.5$ & $83.4 \pm 24.1$ & $97.7 \pm 32.1$ & 0.0002 & 0.004 & $0.63(0.54-0.69)$ \\
\hline $\mathrm{A}(\mathrm{cm} / \mathrm{s})$ & $102.9 \pm 33$ & $103.9 \pm 26.6$ & $102.1 \pm 38.3$ & 0.69 & 0.66 & $0.52(0.5-0.63)$ \\
\hline $\mathrm{E} / \mathrm{A}$ & $1 \pm 0.5$ & $0.9 \pm 0.4$ & $1.1 \pm 0.7$ & 0.0002 & $<0.0001$ & $0.64(0.55-0.7)$ \\
\hline Deceleration time of $E$ wave (ms) & $235.4 \pm 74.3$ & $244.8 \pm 72.0$ & $225.5 \pm 76.0$ & 0.17 & 0.66 & $1.0(1.0-1.0)$ \\
\hline E/E'septal & $19.6 \pm 10.4$ & $17.7 \pm 8.2$ & $21.6 \pm 12.5$ & 0.01 & 0.0006 & $0.63(0.55-0.68)$ \\
\hline PASP (mmHg) & $36.2 \pm 16.3$ & $33 \pm 13.7$ & $38.5 \pm 18.2$ & 0.01 & 0.001 & $0.64(0.55-0.7)$ \\
\hline AV peak velocity $(\mathrm{cm} / \mathrm{s})$ & $390.8 \pm 83.1$ & $383.1 \pm 79.9$ & $397 \pm 85.7$ & 0.20 & 0.63 & $0.52(0.5-0.61)$ \\
\hline AV peak gradient $(\mathrm{mmHg})$ & $63.6 \pm 27$ & $60.6 \pm 25.6$ & $65.9 \pm 28.2$ & 0.13 & 0.58 & $0.52(0.5-0.61)$ \\
\hline $\mathrm{AV}$ mean gradient $(\mathrm{mmHg})$ & $38.8 \pm 17.3$ & $36.6 \pm 16.1$ & $40.5 \pm 18.2$ & 0.09 & 0.83 & $0.51(0.5-0.6)$ \\
\hline AVA index $\left(\mathrm{cm}^{2} / \mathrm{m}^{2}\right)$ & $0.4 \pm 0.12$ & $0.42 \pm 0.13$ & $0.39 \pm 0.12$ & 0.13 & 0.56 & $0.53(0.5-0.61)$ \\
\hline LV stroke work loss (\%) & $58 \pm 10.6$ & $56.4 \pm 10.1$ & $59.6 \pm 11$ & 0.03 & 0.06 & $0.60(0.51-0.72)$ \\
\hline Energy loss index $\left(\mathrm{cm}^{2} / \mathrm{m}^{2}\right)$ & $0.45 \pm 0.17$ & $0.46 \pm 0.21$ & $0.44 \pm 0.13$ & 0.36 & 0.95 & $0.50(0.5-0.62)$ \\
\hline SVR (dyne $\cdot \mathrm{cm} \cdot \mathrm{s}^{-5}$ ) & $1,753 \pm 617.4$ & $1,828.5 \pm 584.3$ & $1,684.1 \pm 647.6$ & 0.10 & 0.11 & $0.58(0.5-0.67)$ \\
\hline $\mathrm{SAC}(\mathrm{ml} / \mathrm{mmHg})$ & $1 \pm 0.4$ & $1 \pm 0.4$ & $0.9 \pm 0.4$ & 0.87 & 0.28 & $0.55(0.5-0.66)$ \\
\hline Valvulo-arterial impedance $\left(\mathrm{mmHg} \cdot \mathrm{ml}^{-1} \cdot \mathrm{m}^{-2}\right)$ & $5.3 \pm 1.7$ & $5.1 \pm 1.5$ & $5.4 \pm 1.8$ & 0.31 & 0.25 & $0.55(0.5-0.63)$ \\
\hline
\end{tabular}

Data given as mean \pm SD.

AV, aortic valve; AVA, aortic valve area; IVSd, interventricular septum diastolic thickness; LAD, left atrial diameter; LASA, left atrial systolic area; LAVI, left atrial volume index; LVDD, LV diastolic diameter; LVEDVi, LV end-diastolic volume index; LVEF, left ventricular ejection fraction; LVESVi, LV end-systolic volume index; LVSD, LV systolic diameter; LVMi, LV mass index; MWT, mean wall thickness; PASP, pulmonary artery systolic pressure; PWd, posterior wall diastolic thickness; SAC, systemic arterial compliance; SVI, stroke volume index; SVR, systemic vascular resistance. Other abbreviations as in Table 1.

\begin{tabular}{|lccc|}
\hline Table 3. Independent Correlates of Death & & \\
Variable & $\begin{array}{c}\text { P-value, }{ }^{\dagger} \text { multivariate } \\
\text { model }^{\ddagger}\end{array}$ & $\begin{array}{c}\text { HR for multivariate } \\
\text { model }^{\S}(\mathbf{9 5} \% \mathbf{~ C l})\end{array}$ & AUC-time $^{\ddagger} \mathbf{~ ( 9 5 \% ~ C l ) ~}$ \\
Age & $<0.0001$ & $3.0(1.8-5.1)$ & $0.74(0.67-0.80)$ \\
Hypertension & 0.02 & $1.8(1.1-3.0)$ & $0.56(0.50-0.67)$ \\
LAD & 0.0004 & $1.7(1.2-2.4)$ & $0.65(0.57-0.69)$ \\
PASP & 0.001 & $1.9(1.3-2.8)$ & $0.63(0.55-0.69)$ \\
\hline
\end{tabular}

†Parsimonious multivariate continuous Cox proportional hazards regression model only including age, hypertension, PASP and LAD, the independent correlates of survival. Multiple imputations were used to test for significance and to generate the HR and $95 \% \mathrm{Cl}$. The AUC-t for the model based on continuous variables was $0.81(95 \% \mathrm{Cl}: 0.76-0.87)$. The joint AUC-t based on 4 dichotomized variables was 0.80 (95\% Cl: 0.73-0.86). ¥Continuous variables; \$dichotomized variables.

AUC-time, area under the curve. Other abbreviations as in Tables 1,2.

LAD and 42-mmHg PASP used jointly maximized AUC at 0.80 (95\% CI: 0.73-0.86). The AUC-t using continuous models was not significantly better than that using dichotomized variables (AUC-t, 0.81; 95\% CI: 0.76-0.87).

A potentially useful clinical tool for estimating the joint im- pact of age, history of hypertension, PASP and LAD on predicting death was devised. "Risk" was defined for each patient as the number of variables among these 4 that exceeded the optimal thresholds. The AUC-t for the risk variables was 0.78 (95\% CI: 0.69-0.82). 


\section{Discussion}

We found that age, history of hypertension, LAD and mildly elevated PASP are independent correlates of all-cause mortality in medically treated elderly patients with severe isolated AS and preserved LVEF. To our knowledge this is the largest study to date of echocardiographic and clinical predictors of death in such patients.

In $44 \%$ of patients meeting the study criteria, surgery was not performed, due to multiple comorbidities, advanced age, patient or family refusal. Given the relative low perioperative mortality in a contemporary series of similar patients undergoing AVR, ${ }^{21}$ it is surprising that such a high proportion still fail to undergo valve replacement. Bach reported on 952 similar patients in a multicenter US cohort of whom $52 \%$ were referred for surgery but only $41 \%$ underwent AVR. ${ }^{7}$ Discrepancies between the present results and those of the Bach study may result from differences in hospital profile. The present institution is a tertiary referral center with a high surgical volume whereas 7 of 10 centers in the Bach study were not. In 179 patients enrolled in the PARTNER study randomized to medical therapy (including balloon valvuloplasty) the rate of death at 2 years was $68 \%$ compared to $41 \%$ in the present study. Compared to the present cohort, patients enrolled in PARTNER had a similar age $(83.2 \pm 8.3$ years vs. $83.2 \pm 7.6$ years $)$ the majority were male ( $84 \%$ vs. $46.5 \%)$, the mean LVEF was lower $(51.1 \pm 14.3 \%$ vs. $64.8 \pm 7.6 \%$ ) and the ineligibility for surgery was based only on high predicted surgical risk and comorbidities. ${ }^{22}$

Use of TAVI may significantly decrease the proportion of patients denied AVR, although a recent study reported only a $10 \%$ decrease in the number of patients not receiving AVR since the introduction of this procedure. ${ }^{23}$ Better risk stratification of this patient group may improve patient selection and outcome.

More advanced age may be associated with frailty and multiple comorbidities. Together, these factors may explain the association of greater age with risk of death in the present study. Other studies have also reported that age is an independent predictor of mortality in patients with preserved ${ }^{24}$ and in those with depressed LVEF. 5

The majority of the present patients had hypertension (80\%), a prevalence higher than that reported in other studies (35$51 \%) .{ }^{25}$ In a recent analysis of 1,616 asymptomatic AS patients enrolled in the SEAS study, the presence of hypertension increased the ischemic event rate by $56 \%$ and mortality by $100 \%$, independent of AS severity. ${ }^{26}$ Similarly, we also found that the presence of hypertension increases the risk of death nearly twofold.

Even mildly elevated pulmonary artery pressure was an independent correlate of mortality, perhaps reflecting the severity of LV diastolic dysfunction, which is found in most patients with severe AS. Other recent evidence also supports the hypothesis that elevated PASP is due mainly to increased LV filling pressure. One study reported that increased E/E' is the most important determinant of PASP in patients with moderate to severe AS. ${ }^{27}$ Mild to moderate pulmonary hypertension was also found to be an independent risk factor in patients undergoing AVR (HR, 4.9; 95\% CI: 1.1-21.8). ${ }^{28}$

The association between LV diastolic dysfunction and adverse outcome has been demonstrated both before and after AVR in studies enrolling relatively small numbers of patients. ${ }^{29,30}$ A recent study enrolling 125 unoperated octogenarians with severe AS and preserved LVEF, 66\% symptomatic, found that correlates of elevated LV filling pressure (transmitral $\mathrm{E} / \mathrm{E}$ ' lateral $>15$, brain natriuretic peptide $>300 \mathrm{ng} / \mathrm{ml}$ ) were inde- pendently associated with death at 1-year follow-up. ${ }^{31}$ But although we found a significant absolute reduction in 1-year survival in patients with $E / E$ ' septal $>15$ compared to those $E / E$ 'septal $\leq 15$, in highly adjusted models this variable was not an independent correlate with death. The discrepancy may be due to the present use of a larger number of clinical and echocardiographic variables than the prior study, some of which had a much higher impact on survival than $\mathrm{E} / \mathrm{E}$ ' septal. The association of increased LA size with mortality also underscores the prognostic importance of LV diastolic function given that LA size is a robust marker of chronic increase in LV filling pressure in the absence of mitral valve disease or atria arrhythmias. Similar findings were reported in patients with severe AS undergoing surgical or non-surgical AVR. ${ }^{32,33}$

The greater strength of LAD vs. biplane LA volume index in the present study as an independent correlate of death was unexpected and requires further evaluation, although another retrospective study reported similar findings in a smaller patient group with different demographics. ${ }^{34}$

Although individual echocardiographic correlates of death have been previously described in patients with severe AS not undergoing AVR, this appears to be the first effort to combine a small number of clinical and echocardiographic variables to assess risk of death in symptomatic, medically treated patients with severe isolated AS and preserved LVEF.

\section{Study Limitations}

The retrospective nature of this study is prone to selection bias and is inherently associated with difficulties in acquiring exhaustive clinical information. Multiple imputation has been performed in order to partially correct for this drawback. This is a single-center study, which limits its generalizability. The present patients, however, were similar to most patients with symptomatic severe AS and normal LVEF and thus this study addresses only patients with a clear indication for early therapeutic intervention. Last, the cause of death could not be determined from the limited data in the Social Security Index and therefore we could not analyze cardiovascular mortality or other reasons of death.

\section{Conclusions}

In patients with severe isolated AS and preserved LVEF treated medically, age, history of hypertension, and any degree of elevated PASP or increased LAD that indicates elevated LV filling pressures secondary to impaired LV diastolic function, are independent correlates of death. Risk increases with the number of factors present. These results, if confirmed by prospective multicenter data, may permit better risk stratification of similar patients in the future.

\section{References}

1. Cowell SJ, Newby DE, Boon NA, Elder AT. Calcific aortic stenosis: Same old story? Age Ageing 2004; 33: 538-544.

2. Lindroos M, Kupari M, Heikkila J, Tilvis R. Prevalence of aortic valve abnormalities in the elderly: An echocardiographic study of a random population sample. J Am Coll Cardiol 1993; 21: 1220-1225.

3. Bonow RO, Carabello B, De Leon AC Jr, Edmunds LH Jr, Fedderly $\mathrm{BJ}$, Freed MD, et al. ACC/AHA guidelines for the management of patients with valvular heart disease. A report of the American College of Cardiology/American Heart Association Task Force on Practice Guidelines (Committee on Management of Patients with Valvular Heart Disease). J Am Coll Cardiol 1998; 32: 1486-1588.

4. Lung B, Cachier A, Baron G, Messika-Zeitoun D, Delahaye F, Tornios $\mathrm{P}$, et al. Decision-making in elderly patients with severe aortic stenosis: Why are so many denied surgery? Eur Heart J 2005; 26: $2714-2720$. 
5. Varadarajan P, Kapoor N, Bansal RC, Pai RG. Clinical profile and natural history of 453 nonsurgically managed patients with severe aortic stenosis. Ann Thorac Surg 2006; 82: 2111-2115.

6. Piérard S, Seldrum S, de Meester C, Pasquet A, Gerber B, Vancraeynest $\mathrm{D}$, et al. Incidence, determinants, and prognostic impact of operative refusal or denial in octogenarians with severe aortic stenosis. Ann Thorac Surg 2011; 91: 1107-1112.

7. Bach DS. Prevalence and characteristics of unoperated patients with severe aortic stenosis. J Heart Valve Dis 2011; 20: 284-291.

8. Kapadia SR, Goel SS, Svensson L, Roselli E, Savage RM, Wallace $\mathrm{L}$, et al. Characterization and outcome of patients with severe symptomatic aortic stenosis referred for percutaneous aortic valve replacement. J Thorac Cardiovasc Surg 2009; 137: 1430-1435.

9. Spaccarotella C, Mongiardo A, Indolfi C. Pathophysiology of aortic stenosis and approach to treatment with percutaneous valve implantation. Circ J 2011; 75: 11-19.

10. Di Eusanio M, Fortuna D, De Palma R, Dell'Amore A, Lamarra M, Contini GA, et al. Aortic valve replacement: Results and predictors of mortality from a contemporary series of 2256 patients. J Thorac Cardiovasc Surg 2011; 141: 940-947.

11. Tamburino C, Capodanno D, Ramondo A, Petronio AS, Ettori F, Santoro G, et al. Incidence and predictors of early and late mortality after transcatheter aortic valve implantation in 663 patients with severe aortic stenosis. Circulation 2011; 123: 299-308.

12. Lung B, Baron G, Butchart EG, Delahaye F, Gohlke-Bärwolf C, Levang OW, et al. A prospective survey of patients with valvular heart disease in Europe: The Euro Heart Survey on Valvular Heart Disease. Eur Heart J 2003; 24: 1231 - 1243.

13. Ding WH, Lam YY, Duncan A, Li W, Lim E, Kaya MG, et al. Predictors of survival after aortic valve replacement in patients with lowflow and high-gradient aortic stenosis. Eur J Heart Fail 2009; 11: 897-902.

14. Shibayama K, Watanabe H, Tabata M, Sasaki S, Fukui T, Umemura $\mathrm{J}$, et al. Impact of ejection fraction on long-term outcome after elective aortic valve replacement in octogenarians with aortic stenosis. Circ J 2012; 76: 1761 - 1767.

15. Meltzer RS, Martin RP, Popp RL. Mitral annular calcification: Clinical and echocardiographic features. Acta Cardiol 1980; 3: 189-202.

16. Barasch E, Gottdiener JS, Larsen KE, Newman AB, Manolio TA. Calcification of the fibrous skeleton of the heart and aortosclerosis in the community dwelling elderly. The Cardiovascular Health Study. Am Heart J 2006; 151: 39-47.

17. Ommen SR, Nishimura RA, Appleton CP, Miller FA, Oh JK, Redfield MM, et al. Clinical utility of Doppler echocardiography and tissue Doppler imaging in the estimation of left ventricular filling pressures: A comparative simultaneous Doppler-catheterization study. Circulation 2000; 102: 1788-1794.

18. Lang RM, Bierig M, Devereux RB, Flachskamp FA, Foster E, Pellikka PA, et al. Recommendations for chamber quantification: A report from the American Society of Echocardiography's Guidelines and Standards Committee and the Chamber Quantification Writing Group, Developed in conjunction with the European Association of Echocardiography, a branch of the European Society of Cardiology. J Am Soc Echocardiogr 2005; 18: 1440-1463.

19. Briand M, Dumesnil JG, Kadem L, Tongue AG, Rieu R, Garcia D, et al. Reduced systemic arterial compliance impacts significantly LV afterload and functions in aortic stenosis: Implications for diagnosis and treatment. J Am Coll Cardiol 2005; 46: 291-298.

20. Rubin DB. Multiple imputation for nonresponse in surveys. New York: John Wiley \& Sons, 1987.

21. Yamane K, Hirose H, Youdelman BA, Bogar LJ, Diehl JT. Conventional aortic valve replacement for elderly patients in the current era. Circ J 2011; 75: 2692-2698.

22. Makkar RR, Fontana GP, Jilaihawi H, Kapadia S, Pichard AD, Douglas PS, et al. PARTNER Trial Investigators. Transcatheter aortic-valve replacement for inoperable severe aortic stenosis. $N$ Engl J Med 2012; 366: 1696-1704.

23. Malaisrie SC, Tuday E, Lapin B, Wang E, Lee R, McGee EC, et al. Transcatheter aortic valve implantation decreases the rate of unoperated aortic stenosis. Eur J Cardiothorac Surg 2011; 40: 43-48.

24. Pierri H, Nussbacher A, Décourt LV, Medeiros C, Cattani A, SerroAzul JB, et al. Clinical predictors of prognosis in severe aortic stenosis in unoperated patients $>$ or $=75$ years of age. Am J Cardiol 2000; 86: $801-804$.

25. Pibarot P, Dusmenil JG. Improving assessment of aortic stenosis. $J$ Am Coll Cardiol 2012; 60: 169-180.

26. Rieck AE, Cramariuc D, Boman K, Gohlke-Bärwolf C, Staal EM, Lønnebakken MT, et al. Hypertension in aortic stenosis: Implications for left ventricular structure and cardiovascular events. Hypertension 2012; 60: 90-97.

27. Casaclang-Verzosa G, Nkomo VT, Sarano ME, Malouf JF, Miller FA $\mathrm{Jr}$, Oh JK. E/Ea is the major determinant of pulmonary artery pressure in moderate to severe aortic stenosis. J Am Soc Echocardiogr 2008; 21: $824-827$.

28. Zuern CS, Eick C, Rizas K, Stoleriu C, Woernle B, Wildhirt S, et al. Prognostic value of mild-to-moderate pulmonary hypertension in patients with severe aortic valve stenosis undergoing aortic valve replacement. Clin Res Cardiol 2012; 101: 81-88.

29. Licker M, Cikirikcioglu M, Inan C, Cartier V, Kalangos A, Theologou $\mathrm{T}$, et al. Preoperative diastolic function predicts the onset of left ventricular dysfunction following aortic valve replacement in high-risk patients with aortic stenosis. Crit Care 2010; 14: R101.

30. Seo JS, Jang MK, Lee EY, Yun SC, Kim DH, Song JM, et al. Evaluation of left ventricular diastolic function after valve replacement in aortic stenosis using exercise Doppler echocardiography. Circ J 2012; 76: $2792-2798$.

31. Biner S, Rafique AM, Goykhman P, Morrissey RP, Naghi J, Siegel RJ. Prognostic value of E/E' ratio in patients with unoperated severe aortic stenosis. JACC Cardiovasc Imaging 2010; 3: 899-907.

32. Lancellotti P, Donal E, Magne J, Moonen M, O'Connor K, Daubert $\mathrm{JC}$, et al. Risk stratification in asymptomatic moderate to severe aortic stenosis: The importance of valvular, arterial and ventricular interplay. Heart 2010; 96: 1364-1371.

33. Gotzmann M, Thiessen A, Lindstaedt M, Mügge A, Ewers A. Left atrial diameter, aortic mean gradient, and hemoglobin for risk stratification in patients undergoing transcatheter aortic valve implantation. Clin Cardiol 2013; 36: 228-234.

34. Rossi A, Tomaino M, Golia G, Anselmi M, Fucá G, Zardini P. Echocardiographic prediction of clinical outcome in medically treated patients with aortic stenosis. Am Heart J 2000; 140: 766-771. 